\title{
Central Lymph Node Metastasis: Is It a Reliable Indicator of Node Involvement in Papillary Thyroid Carcinoma? Letter to the Editor
}

\author{
P. V. Pradeep $\cdot$ S. Kuldeep
}

Published online: 9 March 2010

(C) Société Internationale de Chirurgie 2010

We read with interest the article entitled "Central lymph node metastasis: Is it a reliable indicator of node involvement in Papillary Thyroid Carcinoma? [1]. It is commendable that the World Journal of Surgery has again published another article that has provided some more insights into the controversial topic of the extent of lymph node dissection in papillary thyroid carcinoma. However, we have some questions about the study.

Various studies published and our own experience has shown that lymph node metastasis in the lateral compartment is dependent on several factors, including the patient's age and the primary tumor size [2, 3]. In the present study, the authors state that patients with a tumor size (T) greater than $10 \mathrm{~mm}$ were included. As per their study, 35 patients had absent central and lateral compartment nodes, whereas 9 patients had absent central compartment nodes but positive lateral compartment nodes. The authors failed to mention the $\mathrm{T}$ stage in these patients. Similarly, in 22 patients the central compartment nodes were positive and lateral compartment nodes negative. The $\mathrm{T}$ stage of these patients would have been very interesting and informative to compare with the $\mathrm{T}$ stage of the 55 patients who had positive central and lateral compartment nodes.

We feel that for day-to-day practice the statement that "two or more positive lymph nodes in the central compartment predict lateral node involvement" is not practical. The authors have not clarified whether they have made this observation based on node positivity in the ipsilateral central compartment or the bilateral central compartment. We ourselves have observed that during ultrasound and palpation of the neck during thyroidectomy, small nodes in central compartment are missed which turn out to be positive for metastasis if prophylactic dissection is done. The authors have made these recommendations based on microscopic nodal disease in the central compartment. If the recommendations is based on presence of microscopic disease, then all patients will have to undergo prophylactic central compartment dissection to decide upon the nodal status of the lateral compartment. American Thyroid Association 2009 guidelines recommend that the central compartment need not be dissected if the T stage is less than T3 [4].

\section{References}

1. Xiao GZ, Gao L (2010) Central lymph node metastasis: is it a reliable indicator of node involvement in papillary thyroid carcinoma? World J Surg 34:237-241

2. Rotstein L (2009) The role of lymphadenectomy in the management of papillary carcinoma of thyroid. J Surg Oncol 99:186-188

3. Ito Y, Higashiyama T, Takamura Y et al (2007) Risk factors for recurrence to the lymph node in papillary thyroid carcinoma patients without preoperatively detectable lateral node metastasis: validity of prophylactic lateral neck dissection. World J Surg 31:2085-2091

4. Cooper DS, Doherty GM, Haugen BR et al (2009) Revised American Thyroid Association management guidelines for patients with thyroid nodule and differentiated thyroid cancer. Thyroid 19:1167-1214
P. V. Pradeep $(\square) \cdot$ S. Kuldeep

Department of Endocrine Surgery, Narayana Medical College

and Superspecialty Hospital, Chinthareddypalem, Nellore

524002, AP, India

e-mail: pradeepputhenveetil@yahoo.co.in 